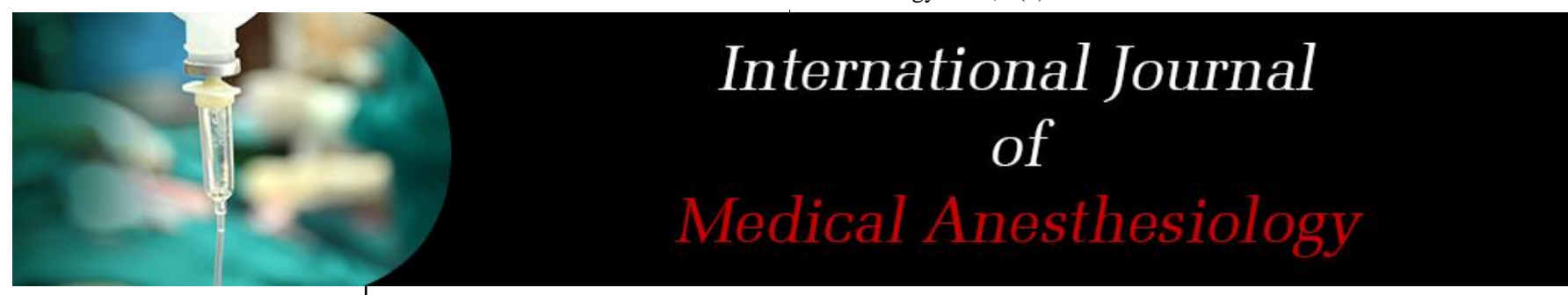

E-ISSN: 2664-3774

P-ISSN: 2664-3766

www.anesthesiologypaper.com

IJMA 2018; 1(1): 36-40

Received: 12-01-2018

Accepted: 09-03-2018

Dr. Sunil Jain

Senior Consultant,

Department of

Anaesthesiology, Metro

Hospital and Cancer Research

Center, Jabalpur, Madhya

Pradesh, India
Corresponding Author:

Dr. Sunil Jain

Senior Consultant,

Department of

Anaesthesiology, Metro

Hospital and Cancer Research

Center, Jabalpur, Madhya

Pradesh, India

\section{Double blinded clinical comparative trial of intrathecal dexmedetomidine and fentanyl as an adjuvant to isobaric levobupivacaine}

\section{Dr. Sunil Jain}

DOI: https://doi.org/10.33545/26643766.2018.v1.i1a.213

\begin{abstract}
Aim: To compare a combination of isobaric Levobupivacaine with fentanyl and dexmedetomidine. Material and methods: This was a prospective, randomized, and double blinded clinical comparative study conducted in the Department of Anaesthesiology Metro Hospital and Cancer Research Center, Jabalpur, Madhya Pradesh, India. The study population consisted of 180 adult patients who were classified as American Society of Anesthesiologists (ASA) physical status I or II, undergoing elective lower limb orthopaedic surgery under spinal anesthesia. The study participants were randomly divided into three groups. Group A: $0.5 \%$ Levobupivacaine Isobaric $2.5 \mathrm{ml}+0.5 \mathrm{ml}$ normal saline (total volume is upto $3.0 \mathrm{ml}$ ). Group F: $0.5 \%$ Levobupivacaine Isobaric $2.5 \mathrm{ml}+25 \mathrm{mug}$ fentanyl (test solution will diluted with normal saline to total volume of $3.0 \mathrm{ml}$ ). Group D: $0.5 \%$ Levobupivacaine isobaric $2.5 \mathrm{ml}$ +5 mcg dexmedetomidine (test solution will diluted with normal saline to total volume of $3.0 \mathrm{ml}$.

Result: The mean time for onset of sensory block was $10.74 \pm 4.11 \mathrm{~min}$ in the saline group and $8.56 \pm 2.89 \mathrm{~min}$ in the dexmedetomidine group and $2.18 \pm 1.32 \mathrm{~min}$ in the fentanyl group. The mean time taken to achieve maximum sensory block in group A was $15.78 \pm 4.93 \mathrm{~min}$, in group D was $13.36 \pm 3.62$ min and in group F it was $5.42 \pm 1.87$ min so maximum sensory block was achieved earlier in group. Peak level of sensory block attained in the fentanyl group was T4 and the peak level of sensory block in dexmedetomidine group was T6 and in the saline group peak level was T8. So the highest sensory block was attained in the fentanyl group.

Conclusion: Dexmedetomidine group has longer onset of and duration of sensory block and effective postoperative analgesia and fewer side effects as compared to fentanyl group.
\end{abstract}

Keywords: Subarachnoid block, levobupivacaine

\section{Introduction}

Spinal anesthesia is the most commonly used technique for lower abdominal surgeries as it is very economical and easy to administer. However, postoperative pain control is a major problem because spinal anesthesia using only local anesthetics is associated with relatively short duration of action and thus early analgesic intervention is needed in the postoperative period. A number of adjuvants, such as clonidine and midazolam and others have been studied to prolong the effect of spinal anesthesia ${ }^{[1,2]}$. A common problem during lower abdominal surgeries under spinal anesthesia is visceral pain, nausea, and vomiting ${ }^{[3]}$. Some drugs have been used as adjuvants in spinal anesthesia to prolong intraoperative and postoperative analgesia including opioids, $\alpha 2$ agonists, neostigmine, vasoconstrictors, etc. Clonidine and dexmedetomidine are two $\alpha 2$ agonists affecting via pre- and post-synaptic $\alpha 2$ receptors ${ }^{[4]}$. Dexmedetomidine has been widely used for anesthesia and analgesic purposes. This drug has sedative, anti-anxiety, analgesic, neuroprotective, and anesthetic-sparing effects ${ }^{[5]}$. Dexmedetomidine along with other drugs have been used to increase the duration of analgesia in subarachnoid, epidural and caudal blocks ${ }^{[6,7]}$. Levobupivacaine causes less cardiovascular and neurological events. Onset of sensory and motor block is hastened with Hyperbaric Levobupivacaine compared to Isobaric Levobupivacaine. Increased protein binding and higher clearance explains cardiostability of Levobupivacaine ${ }^{[8]}$. Fentanyl is a synthetic opioid with central action, which is used widely for pain control. Intrathecal fentanyl is usually added to other local anesthetics to increase anesthesia and analgesia. It has improved spinal anesthesia and reduced the anesthetic drug related side effects including pruritus, nausea and vomiting ${ }^{[9]}$. Dexmedetomidine and fentanyl have been used as adjuvant to local anesthetics in different surgeries to provide superior analgesia and to improve the 
duration of the block ${ }^{[10-12]}$. In this study we propose to compare a combination of isobaric Levobupivacaine with fentanyl and dexmedetomidine for the characteristics of spinal blockade with respect to onset, duration and hemodynamic parameters and side effect.

\section{Material and Methods}

This was a prospective, randomized, and double blinded clinical comparative study conducted in the Department of Anaesthesiology Metro Hospital and Cancer Research Center, Jabalpur, Madhya Pradesh, India. after taking the approval of the protocol review committee and institutional ethics committee.

\section{Methodology}

We evaluate the effect, hemodynamic stability and adverse effects of using intrathecal dexmedetomidine and fentanyl as an adjuvant to Isobaric Levobupivacaine for lower limb orthopaedic surgery. The study participants were randomly divided into three groups.

The study population consisted of 180 adult patients who were classified as American Society of Anesthesiologists (ASA) physical status I or II, undergoing elective lower limb orthopaedic surgery under spinal anesthesia. 180 patients with age between 20 to $60 \mathrm{yrs}$ of either sex, ASA 1 and 2 and Patient posted for elective lower limb orthopaedic surgeries were include in this study. Patients who had History of allergy to study drugs and Patients using alpha 2adrenergic receptors antagonists, calcium channel blockers, angiotensin-converting enzyme inhibitor were exclude from the study.

All patients were preloaded with Ringer lactate solution $10 \mathrm{ml} / \mathrm{kg}$ over 15 minutes before the spinal anaesthesia. The base line heart rates, systolic, diastolic and mean Blood pressure, $\mathrm{SpO} 2$ respiratory rate, were recorded. Then after Subarachnoid Block, all the parameters like pulse rate, systolic blood pressure, diastolic blood pressure, mean arterial pressure, SPO2, respiratory rate, level of sensory block, grade of motor block, sedation scale at every 1 minute for 5 minutes; then every 5 minutes till 30 minutes and then every $15 \mathrm{~min}$ up to $2 \mathrm{hrs}$ and then after every 30 min till the end of surgery. In the postoperative period following parameters are observed pulse, systolic blood pressure, diastolic blood pressure, mean arterial pressure, SPO2, VAS, 1st rescue analgesic requirement, total analgesic requirement in $24 \mathrm{hr}$ period, sedation scale and side effect were recorded immediately in postoperative recovery room, $0.5 \mathrm{hr}, 1 \mathrm{hr}, 1.5 \mathrm{hr}, 2 \mathrm{hr}, 3 \mathrm{hr}, 4 \mathrm{hr}, 8 \mathrm{hr}, 12 \mathrm{hr}$, $18 \mathrm{hr}, 24 \mathrm{hr}$ period.

- Group A: 0.5\% Levobupivacaine Isobaric $2.5 \mathrm{ml}+0.5 \mathrm{ml}$ normal saline (total volume is upto $3.0 \mathrm{ml}$ ).

- Group F: 0.5\% Levobupivacaine Isobaric $2.5 \mathrm{ml}+$ 25mug fentanyl (test solution will diluted with normal saline to total volume of $3.0 \mathrm{ml}$ ).

- Group D: $0.5 \%$ Levobupivacaine isobaric $2.5 \mathrm{ml}+5 \mathrm{mcg}$ dexmedetomidine (test solution will diluted with normal saline to total volume of $3.0 \mathrm{ml}$.

Sensory anesthesia assessed by loss of sharp sensation to pinprick test in the midclavicular line. Motor blockade was determined using Modified Bromage scale.

\section{Result}

The mean time for onset of sensory block was $10.74 \pm 4.11$ $\mathrm{min}$ in the saline group and $8.56 \pm 2.89 \mathrm{~min}$ in the dexmedetomidine group and $2.18 \pm 1.32$ min in the fentanyl group. The mean time taken to achieve maximum sensory block in group A was $15.78 \pm 4.93 \mathrm{~min}$, in group D was $13.36 \pm 3.62 \mathrm{~min}$ and in group $\mathrm{F}$ it was $5.42 \pm 1.87 \mathrm{~min}$ so maximum sensory block was achieved earlier in group. Peak level of sensory block attained in the fentanyl group was T4 and the peak level of sensory block in dexmedetomidine group was T6 and in the saline group peak level was T8. So the highest sensory block was attained in the fentanyl group. The mean duration of sensory block in group A was $114.63 \pm 7.25 \mathrm{~min}$, and in group $\mathrm{F}$ was $162.32 \pm 12.84 \mathrm{~min}$., and in group D was $205.17 \pm 6.52 \mathrm{~min}$. Prolong duration occur in the dexmedetomidine group. The prolongation of effect may result from synergism between local anaesthetic and alpha 2 adrenoceptor agonist action. The mean onset time of motor block in group A was $11.11 \pm 3.87 \mathrm{~min}$, in group $\mathrm{D}$ it was $8.79 \pm 3.54 \mathrm{~min}$, in group $\mathrm{F}$ it was 3.45 $\pm 1.29 \mathrm{~min}$. Onset of motor block occurred earlier in the fentanyl group. In the present study there was a significant difference in duration of motor block across the three groups with $\mathrm{p}$ value $<0.001$. In group a mean duration of motor block was $162.04 \pm 6.52 \mathrm{~min}$ and in group $\mathrm{D}$ was $254.29 \pm 6.72 \mathrm{~min}$ and in group $\mathrm{F}$ it was $187.88 \pm 11.26 \mathrm{~min}$. There was a significant difference in the pulse rate, systolic blood pressure, diastolic blood pressure and mean arterial blood pressure from the $2 \mathrm{~min}$ to $20 \mathrm{~min}$ in the intraoperative period. In the postoperative time period the pulse rate, systolic blood pressure, diastolic blood pressure, mean blood pressure was not statistically significant with $\mathrm{p}$ value of $>0.05$. In regard, first analgesic requirement was prolonged in group $\mathrm{D}$ as compared to group $\mathrm{A}$ and group $\mathrm{F}$ and requirement of $24 \mathrm{hr}$ analgesia was also found lower in the dexmedetomidine group, and however supplementary analgesia in the form of diclofenac $75 \mathrm{mg}$ IV was required in group a only. No patient in any of the groups had side effects like shivering, pruritus, nausea vomiting and no patient had episode of respiratory depression. There was 38 $(63.33 \%)$ patient in the dexmedetomidine group had bradycardia while in the fentanyl group $5(8.33 \%)$ patients and in the saline group $3(5 \%)$ patients had bradycardia being statistically significant.

Table 1: Comparison of demographic parameters

\begin{tabular}{|c|c|c|c|c|}
\hline \multirow{2}{*}{ Parameters } & Group A & Group D & Group F & \\
\hline & $(n=60)$ & $(n=60$ & $(n=60$ & P-value \\
\hline Age (years) [mean \pm SD] & $35.21 \pm 9.61$ & $36.89 \pm 14.23$ & $37.89 \pm 14.68$ & $0.558(\mathrm{NS}) \dagger$ \\
\hline \multicolumn{5}{|l|}{ Gender [No. (\%)] } \\
\hline Male & $41(68.33)$ & $46(76.67)$ & $39(65)$ & \multirow{2}{*}{$0.569(\mathrm{NS})^{*}$} \\
\hline Female & $19(31.67)$ & $14(23.33)$ & $21(35)$ & \\
\hline \multicolumn{5}{|l|}{ ASA } \\
\hline 1 & $57(95)$ & $55(91.67)$ & $55(91.67)$ & \multirow{2}{*}{$0.669(\mathrm{NS})^{*}$} \\
\hline 2 & $3(5)$ & $5(8.33)$ & $5(8.33)$ & \\
\hline
\end{tabular}




\begin{tabular}{|c|c|c|c|c|}
\hline Weight $($ mean \pm SD) & $64.29 \pm 2.69$ & $64.32 \pm 1.74$ & $64.98 \pm 2.12$ & $0.475(\mathrm{NS})$ \\
\hline Height $($ mean \pm SD) & $160.12 \pm 2.61$ & $160.81 \pm 2.84$ & $160.19 \pm 3.18$ & $0.587(\mathrm{NS})$ \\
\hline Duration of surgery (mean \pm SD) & $91.77 \pm 16.65$ & $98.26 \pm 18.42$ & $99.87 \pm 13.36$ & $0.059(\mathrm{NS})$ \\
\hline
\end{tabular}
* Obtained using ANOVA, S: Significant, NS: Not Significant, $\ddagger$ First significant drop
compared to baseline.

Table 2: Comparison of Sensory and Motor block parameters across three groups

\begin{tabular}{|c|c|c|c|c|c|c|c|}
\hline \multirow{3}{*}{ Parameters } & \multicolumn{6}{|c|}{ Mean \pm SD } & \multirow{3}{*}{ P-value } \\
\hline & \multirow{2}{*}{\multicolumn{2}{|c|}{\begin{tabular}{|c|} 
Group A \\
$(\mathbf{n}=\mathbf{6 0})$ \\
\end{tabular}}} & \multirow{2}{*}{\multicolumn{2}{|c|}{\begin{tabular}{|c|} 
Group D \\
$(\mathbf{n}=60$ \\
\end{tabular}}} & \multirow{2}{*}{\multicolumn{2}{|c|}{$\begin{array}{c}\text { Group F } \\
(n=60)\end{array}$}} & \\
\hline & & & & & & & \\
\hline Onset of s & 10.74 & 4.11 & 8.56 & 2.89 & 2.18 & 1.32 & $<0.001 *(\mathrm{~S})$ \\
\hline Duration of se & 114.63 & 37.25 & 205.17 & 76.52 & 162.32 & 12.84 & $<0.001 *(\mathrm{~S})$ \\
\hline Ons & 11.11 & 3.87 & 8.79 & 3.54 & 3.45 & 1.29 & $<0$. \\
\hline Dura & 162.04 & 6.52 & 254.29 & 96.72 & 187.88 & 11.26 & $<0$. \\
\hline $\begin{array}{r}\text { Time taken to } \\
\text { sensor }\end{array}$ & 15.78 & 4.93 & 13.36 & 3.62 & 5.42 & 1.87 & $<0$. \\
\hline Bron & & & & {$[1$} & $(\%)]$ & & \\
\hline $\begin{array}{r}\text { 3: Inability to } \\
\text { ankle }\end{array}$ & 60 & 10 & 60 & 1 & 60 & 100 & $<0.00$ \\
\hline
\end{tabular}

$*$ Obtained using ANOVA, $\uparrow$ obtained using Chi-square test, S: Significant.

Table 3: Comparison of maximum sensory block attained in three groups

\begin{tabular}{|c|c|c|c|c|}
\hline $\begin{array}{c}\text { Maximum sensory } \\
\text { block attained }\end{array}$ & $\begin{array}{c}\text { Group A } \\
(\mathbf{n}=60)\end{array}$ & $\begin{array}{c}\text { Group D } \\
(n=60)\end{array}$ & $\begin{array}{c}\text { Group F } \\
(\mathbf{n}=\mathbf{6 0})\end{array}$ & $\begin{array}{c}\text { P- } \\
\text { value* }\end{array}$ \\
\hline T4 dense & 0 & 0 & $4(6.67)$ & \multirow{4}{*}{$\begin{array}{l}<0.001 \\
\quad(\mathrm{~S})\end{array}$} \\
\hline T6 dense & 0 & $8(13.33)$ & $43(71.67)$ & \\
\hline T8 dense & $10(16.67)$ & $34(56.67)$ & $13(21.66)$ & \\
\hline T10 dense & $50(83.33)$ & $18(30)$ & 0 & \\
\hline
\end{tabular}

*Obtained using Chi square test, S: Significant3

Table 4: Frequency distribution according to first analgesic requirement in patients-Post operative period

\begin{tabular}{|c|c|}
\hline Post-operative first analgesic requirement & No. (\%) \\
\hline \multicolumn{2}{|c|}{ Group A } \\
\hline Intraoperative & $28(46.67))$ \\
\hline Postoperative recovery & $15(25)$ \\
\hline $0.5 \mathrm{hr}$ & $17(28.33)$ \\
\hline $2 \mathrm{hr}$ & $3(5)$ \\
\hline $3 \mathrm{hr}$ & $13(21.67)$ \\
\hline $4 \mathrm{hr}$ & $28(46.67)$ \\
\hline $6 \mathrm{hr} \quad 16(26.67)$ \\
\hline \multicolumn{2}{|c|}{ Group D F } \\
\hline $0.5 \mathrm{hr}$ & $7(11.67)$ \\
\hline $1 \mathrm{hr}$ & $29(48.33)$ \\
\hline $2 \mathrm{hr}$ & $18(30)$ \\
\hline
\end{tabular}

Table 5: Frequency distribution according to total analgesic requirement in $24 \mathrm{hr}$-Postoperative period

\begin{tabular}{|c|c|}
\hline Group/Number of doses in $24 \mathrm{hr}$. & No. $(\%)$ \\
\hline \multicolumn{2}{|l|}{ Group A } \\
\hline 4 & $21(35)$ \\
\hline 5 & $31(53.33)$ \\
\hline 6 & $8(13.33)$ \\
\hline \multicolumn{2}{|l|}{ Group D } \\
\hline 1 & $4(6.67)$ \\
\hline 2 & $54(90)$ \\
\hline 3 & $2(3.33)$ \\
\hline \multicolumn{2}{|l|}{ Group F } \\
\hline 1 & $5(8.33)$ \\
\hline 2 & $10(16.67)$ \\
\hline 3 & $45(75)$ \\
\hline
\end{tabular}

\section{Discussion}

In this study we compared the $5 \mathrm{mcg}$ dose of dexmedetomidine with $25 \mathrm{mcg}$ dose of fentanyl administered to the Isobaric Levobupivacaine. There were very few studies that compared both the doses simultaneously with Isobaric Levobupivacaine; we have compared and discussed our results with various other studies using similar adjuvants in same doses but in combination with various local anaesthetic as well in various surgeries. The values of the demographic variables were comparable between the three groups. Onset of sensory block defined as time taken to attain the T12 dermatomal level. Our study showed the mean time for onset of sensory block was $10.74 \pm 4.11 \mathrm{~min}$ in the saline group and $8.56 \pm 2.89 \mathrm{~min}$ in the dexmedetomidine group and $2.18 \pm 1.32 \mathrm{~min}$ in the fentanyl group. So onset of sensory block occurred earlier in the fentanyl group Mohamad Kamal et al., in $2017^{[13]}$ found that the onset of sensory block was $3.22 \pm 0.69 \mathrm{~min}$ in the group $\mathrm{F}$ and $3.90 \pm 0.94 \mathrm{~min}$ in the group $\mathrm{D}$ with $\mathrm{p}$ value highly significant $p<0.001$. Shelly Rana ${ }^{[14]}$ in 2017 stated that the earlier onset with fentanyl can be attributed to its lipophilic properties. The lipophilic opioids rapidly traverse the dura mater, where they are sequestered in the epidural fat and enter the systemic circulation; they also rapidly penetrate the spinal cord where they binds opioid receptors within the white matter as well as dorsal horn receptors and eventually enter the systemic circulation as they are cleared from the spinal cord. Al Ghanem et al., $2009^{[15]}$ found the onset time for sensory block was upto T10 level and it was 7.5 $\pm 7.4 \mathrm{~min}$ in dexmedetomidine group and 7.4 $\pm 3.3 \mathrm{~min}$ in fentanyl. The mean time taken to achieve maximum sensory block in group A was $15.78 \pm 4.93 \mathrm{~min}$, in group D was $13.36 \pm 3.62$ min and in group $\mathrm{F}$ it was $5.42 \pm 1.87 \mathrm{~min}$ so maximum sensory block was achieved earlier in group. Nayagam HA et al., (2014) ${ }^{[16]}$ found that the mean time for peak sensory levels was $(11.88 \pm 2.156) \mathrm{min}$ in fentanyl group and in dexmedetomidine group it was $(12.92 \pm 3.131) \mathrm{min}$. The difference between the two means was statistically significant. $(p<0.05)$. Al Ghanem et al., in $2009^{[15]}$ studied and found that time to reach the maximum sensory block was around $19.34 \pm 2.87 \mathrm{~min}$ in the dexmedetomidine group 
and $18.39 \pm 2.46 \mathrm{~min}$ in the fentanyl group which was statistically insignificant with $\mathrm{p}$ value of 0.12 .

Peak level of sensory block attained in the fentanyl group was T4 and the peak level of sensory block in dexmedetomidine group was T6 and in the saline group peak level was T8. So the highest sensory block was attained in the fentanyl group. Ghanem M Subhi et al., [15] (2009) found out that highest sensory level was T6 in the Dexmedetomidine group and in the fentanyl group it was around T8 level. The mean duration of sensory block in group A was $114.63 \pm 7.25 \mathrm{~min}$, and in group $\mathrm{F}$ was $162.32 \pm 12.84 \mathrm{~min}$. and in group D was $205.17 \pm 6.52 \mathrm{~min}$. Prolong duration occur in the dexmedetomidine group. Prolong duration occur in the dexmedetomidine group. The prolongation of effect may result from synergism between local anaesthetic and alpha 2 adrenoceptor agonist action. Ahmed Basuni et al., [17] in 2013 also stated the prolongation of the block in the dexmedetomidine.

In our study the mean onset time of motor block in group A was $11.11 \pm 3.87 \mathrm{~min}$, in group D it was $8.79 \pm 3.54 \mathrm{~min}$, in group $\mathrm{F}$ it was $3.45 \pm 1.29 \mathrm{~min}$ Onset of motor block occurred earlier in the fentanyl group. Mohamad Kamal et al., in $2017^{[13]}$ found that onset of motor block was $3.74 \pm 0.57 \mathrm{~min}$ in the group $\mathrm{F}$ and $4.44 \pm 0.91 \mathrm{~min}$ in the group $\mathrm{D}$ with $\mathrm{p}$ value $<0.001$. In the present study there was a significant difference in duration of motor block across the three groups with $\mathrm{p}$ value $<0.001$. In group $\mathrm{A}$ mean duration of motor block was $162.04 \pm 6.52 \mathrm{~min}$ and in group $\mathrm{D}$ was $254.29 \pm 6.72 \mathrm{~min}$ and in group $\mathrm{F}$ it was $187.88 \pm 11.26 \mathrm{~min}$. Mahendru et al., (2013) [18] found that duration of motor block was $(161.5 \pm 19.8 \mathrm{~min})$ in saline group. (196.0 \pm 26.8$)$ min in group fentanyl and $(198.7 \pm 26.4 \mathrm{~min})$ in clonidine, $(273.3 \pm 24.6) \mathrm{min}$ in the dexmedetomidine group $(P<$ 0.0001). Dr. Rayees Ahmad et al., $2016^{[19]}$ found duration of motor block in the fentanyl group was around $152.90 \pm 8.31 \mathrm{~min}$ and in the dexmedetomidine group it was around $419.70 \pm 16.85 \mathrm{~min} .(p<0.001)$.

In the present study there was a significant difference in the pulse rate, systolic blood pressure, diastolic blood pressure and mean arterial blood pressure from the $2 \mathrm{~min}$ to $20 \mathrm{~min}$ in the intraoperative period. In the postoperative time period the pulse rate, systolic blood pressure, diastolic blood pressure, mean blood pressure was not statistically significant with $p$ value of $>0.05$. Khan A L et al., (2015) ${ }^{[20]}$ inferred that the heart rate at all intervals was lower in dexmedetomidine group when compared to fentanyl group. Rao et al. in $2015^{[21]}$ found that the significant decrease in the pulse rate was observed in the dexmedetomidine group as compared to the fentanyl and control. Ahmed Sobhy Basuni et al., (2013) [17] found that blood pressure was comparable in the two groups throughout the surgery. 3 patients in group $\mathrm{F}$ showed intraoperative period hypotension. Mohamad Kamal et al., in $2017^{[13]}$ stated that hypotension occur in both the groups but the value was not statistically significant in using the intravenous vasopressor therapy.

Mechanism of sedation in the dexmedetomidine group is due to action on the sleep promoting pathway. In the present study both intraoperative and postoperative period dexmedetomidine contribute to sedation scale 2. Rajani Gupta R et al., (2011) ${ }^{[22]}$ stated that the mean sedation score was $(3.8 \pm 0.5)$ in group dexmedetomidine as compared to $(2.2 \pm 0.53)$ in group fentanyl $(P<0.05)$. Rayees Ahmad R et al., (2016) ${ }^{[19]}$ found the mean sedation score for group dexmedetomidine was $(3.40 \pm 0.49)$ and in fentanyl was (2.16 \pm 0.37$),(P<0.001)$. There was no significant difference between the three groups in the respiratory rate. Similar to Ahmed Sobhy Basuni et al., in $2013^{[17]}$ and R. Ahmed et al. in 2009. [19] In regard, first analgesic requirement was prolonged in group D as compared to group A and group F and requirement of $24 \mathrm{hr}$ analgesia was also found lower in the dexmedetomidine group, and however supplementary analgesia in the form of diclofenac $75 \mathrm{mg}$ iv was required in group A only.

Aamir Laique Khan et al. in $2015^{[20]}$ studied that the time for first analgesic requirement in the dexmedetomidine group was $(280 \pm 7.84)$ min and in the fentanyl group it was $(173.88 \pm 8.12) \mathrm{min}$ after the starting of surgery which was highly significant with $\mathrm{p}$ value of $(<0.001)$.

Farhad Safari, et al., in $2016^{[23]}$ Total morphine doses in 24 hours was significantly lower in the dexmedetomidine group as compared to fentanyl and control groups $(P<0.05)$.

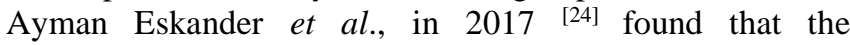
postoperative analgesic requirement in first $24 \mathrm{hr}$ was significantly lower in the dexmedetomidine and the fentanyl group compared to the control group and it was significantly lower in the dexmedetomidine group than fentanyl group $(p<0.05)$.

In the present study no patient had episode of respiratory depression. Vidhi Mahendru et al., in $2013^{[18]}$ Rajani Gupta et al., 2011221 in both the studies there was no evidence of respiratory depression. In the present study no patient in any of the groups had side effects like shivering, pruritus, nausea vomiting, similar to Ahmed Sobhy Basuni et al., 2013. Al Ghanem et al., in $2009^{[15]}$ stated that that $2(5 \%)$ patients in the dexmedetomidine group and $4(10 \%)$ patients in the Fentanyl group had nausea and vomiting with $\mathrm{p}$ value of 0.401 , no patient in the dexmedetomidine group got pruritus and 5 patients in the fentanyl group had pruitu.

Gupta R et al., (2011) [22] studied intrathecally dexmedetomidine and fentanyl as adjuvant to Bupivacaine in lower abdominal surgeries. In group dexmedetomidine only one patient had Nausea and no patient had vomiting while in group fentanyl two patients had nausea and one patient had vomiting. One patient in the fentanyl group had pruritus. In the present study $38(63.33 \%)$ patient in the dexmedetomidine group had bradycardia while in the fentanyl group $5(8.33 \%)$ patients and in the saline group 3 $(5 \%)$ patients had bradycardia being statistically significant. However there was no episode of bradycardia found in Ahmed Sobhy Basuni et al., [17] in 2013 and Mohamad Kamal et al., in $2017^{[13]}$ studies. Ghanem et al., in $2009^{\text {[15] }}$ stated that side effect of bradycardia was less because small dose of intrathecal dexmedetomidine was used in their study. In our study, 41 patients in the fentanyl group had episode of hypotension. Which was treated with inj mephentermine $3 \mathrm{mg}$ in incremental doses. The maximum hypotension occur in the F Ahmad R et al., (2016) [19] studied they found that $14(28.0 \%)$ patients in group fentanyl and $8(16.0 \%)$ patients in group dexmedetomidine had hypotension.

\section{Conclusion}

Dexmedetomidine group has longer onset of and duration of sensory block and effective postoperative analgesia and fewer side effects as compared to fentanyl group. 


\section{Reference}

1. Elia N, Culebras X, Mazza C, Schiffer E, Tramèr MR. Clonidine as an adjuvant to intrathecal local anesthetics for surgery: systematic review of randomized trials. Reg. Anesth Pain Med 2008;33(2):159-67.

2. Boussofara M, Carlès M, Raucoules-Aimé M, Sellam MR, Horn JL. Effects of intrathecal midazolam on postoperative analgesia when added to a bupivacaineclonidine mixture. Reg. Anesth Pain Med 2006;31(6):501-5.

3. Alahuhta S, Kangas-Saarela T, Hollmén AI, Edström HH. Visceral pain during caesarean section under spinal and epidural anaesthesia with bupivacaine. Acta Anaesthesiol Scand 1990;34:95-8.

4. Shah A, Patel I, Gandhi R. Haemodynamic effects of intrathecal dexmedetomidine added to ropivacaine intraoperatively and for postoperative analgesia. Int. J Basic Clin Pharmacol 2013;2(1):26-9.

5. Panzer O, Moitra V, Sladen RN. Pharmacology of sedative-analgesic agents: Dexmedetomidine, remifentanil, ketamine, volatile anesthetics, and the role of peripheral mu antagonists. Crit. Care Clin 2009;25(3):451-69.

6. Bekker A, Sturaitis M, Bloom M, Moric M, Golfinos J, Parker $\mathrm{E}$ et al. The effect of dexmedetomidine on preoperative hemodynamics in patients undergoing craniotomy. Anesth Analg 2008;107(4):1340-7.

7. Sudheesh K, Harsoor S. Dexmedetomidine in anaesthesia practice: a wonder drug? Indian J Anaesth 2011;55(4):323-4.

8. Borgeat A, Aguirre J. Update on local anesthetics. Curr. Opin Anaesthesiol 2010;23(4):466-471.

9. Liu SS, McDonald SB. Current issues in spinal anesthesia. Anesthesiology 2001;94(5):888-906.

10. Mohamed T, Susheela I, Balakrishnan BP, Kaniyil S. Dexmedetomidine as adjuvant to lower doses of intrathecal bupivacaine for lower limb orthopedic surgeries. Anesth Essays Res 2017;11(3):681-5.

11. Saadalla AET, Khalifa OYA. Influence of Addition of Dexmedetomidine or Fentanyl to Bupivacaine Lumber Spinal Subarachnoid Anesthesia for Inguinal Hernioplasty. Anesth Essays Res 2017;11(3):554-7.

12. Farooq N, Singh RB, Sarkar A, Rasheed MA, Choubey S. To evaluate the efficacy of fentanyl and Dexmedetomidine as adjuvant to Ropivacaine in brachial plexus block: a double-blind, prospective. Randomized Study Anesth Essays Res. 2017;11(3):7309.

13. Kamal MH, Ibrahim JH, Saaed AA, Zayed MS, Magdy M. Comparison of Intrathecal Dexmedetomidine and Fentanyl as Adjuvants to Levobupivacaine in Parturients Undergoing Elective Cesarean Sections. Med J Cairo Univ 2017;85(2):593-600.

14. Shelly MP. Dexmedetomidine: a real innovation or more of the same? Br J Anaesth 2001, 677-678.

15. Al-Ghanem SM, Massad IM, Al-Mustafa MM, AlZaben KR, Qudaisat IY, Qatawneh AM et al., Effect of adding dexmedetomidine versus fentanyl to intrathecal bupivacaine on spinal block characteristics in gynecological procedures: A double blind controlled study. Am J Appl. Sci 2009;6(5):882-887.

16. Nayagam HA, Ratan Singh N, Shanti Singh H. A prospective randomised double blind study of intrathecal fentanyl and dexmedetomidine added to low dose bupivacaine for spinal anesthesia for lower abdominal surgeries. Indian J Anaesth 2014;58(4):430-435.

17. Basuni AS, Ezz HAA. Dexmedetomidine as supplement to low-dose levobupivacaine spinal anesthesia for knee arthroscopy. Egypt J Anaesth 2014;30(2):149-153.

18. Mahendru V, Tewari A, Katyal S, Grewal A, Singh Mr, Katyal R. A comparison of intrathecal dexmedetomidine, clonidine, and fentanyl as adjuvants to hyperbaric bupivacaine for lower limb surgery: A double blind controlled study. J Anaesthesiol Clin Pharmacol 2013;29(4):496.

19. Ahmad R. A Comparative Study of Intrathecal Low Dose Bupivacaine and Dexmedetomidine with Low Dose Bupivacaine and Fentanyl. IOSR J Dent Med Sci 2016;15(4):09-17.

20. Khan AL, Singh RB, Tripathi RK, Choubey S. A comparative study between intrathecal dexmedetomidine and fentanyl as adjuvant to intrathecal bupivacaine in lower abdominal surgeries: A randomized trial. Anesth essays Res 2015;9(2):139-148.

21. Rao S. A Comparative Study of Intrathecal Dexmedetomidine and Fentanyl as Adjuvants to Bupivacaine for Infra-Umbilical Surgeries. J Evol Med Dent Sci. [Internet] 2015;4(6):962-967.

22. Verma R, Kohli M, Kushwaha J, Gupta R, Bogra J, Raman R. A Comparative study of intrathecal dexmedetomidine and fentanyl as adjuvants to Bupivacaine. J Anaesthesiol Clin Pharmacol 2011;27(3):339.

23. Safari F, Aminnejad R, Mohajerani SA, Farivar F, Mottaghi K, Safdari H. Intrathecal Dexmedetomidine and Fentanyl as Adjuvant to Bupivacaine on Duration of Spinal Block in Addicted Patients. Anesthesiol Pain Med 2016;6(1):1-8.

24. Ayman Eskander T Saadalla and Osama Yehia A Khalifa. Influence of Addition of Dexmedetomidine or Fentanyl to Bupivacaine Lumber Spinal Subarachnoid Anesthesia for Inguinal Hernioplasty. Anaesth essay Res 2017;11(3):554-557 